\title{
ESTRATEGIAS EMPRESARIALES Y CAMBIO ESTRUCTURAL DURANTE LA CONVERTIBILIDAD*
}

\author{
LUCAS M. GÓMEZ TONSICH \\ FACULTAD DE CIENCIAS ECONÓMICAS - UNNE
}




\title{
RESUMEN
}

l documento indaga de qué formas respondieron los agentes económicos locales a los
desafíos y oportunidades que suponía la implementación del Régimen de Convertibi-
lidad; para lo cual se contextualiza el mismo en el marco de las transformaciones que
se venían operando en el orden económico internacional a partir de la década de 1970, señalándose además las dificultades que experimentaba el patrón de desarrollo por sustitución de importaciones vigente en América Latina por entonces.

Seguidamente se analizan las condiciones que derivaron en la crisis hiperinflacionaria argentina de 1989 y 1990 -en el marco del modelo de valorización financiera introducido en el país a partir de 1976- y que sirvieron de antesala a la implementación del Régimen de Convertibilidad; para luego reseñar brevemente cuáles fueron los principales rasgos de dicho plan económico signado por la fijación del tipo de cambio, la desregulación de la economía, la apertura comercial y la venta de activos públicos.

Finalmente se exponen las estrategias adoptadas por las empresas locales a la luz de las oportunidades y desafíos que se les presentaban, caracterizadas por la disminución del número de establecimientos productivos, el aumento del grado de apertura comercial, un proceso de inversiones basado en la adquisición de equipos importados, el aumento de la concentración y la extranjerización de la economía y la caída abrupta del coeficiente de valor agregado; para concluir con un resumen de las modificaciones que dichas estrategias produjeron en la morfología del aparato productivo del país, destacándose el fuerte impulso a los servicios -especialmente en el caso del sector financiero- y la reducción del valor agregado en la producción de bienes a favor de las actividades intensivas tanto en capital como en recursos naturales.

Palabras clave: Convertibilidad - Estrategia Empresarial - Estructura del PIB.

\begin{abstract}
The paper explores in what ways local traders responded to the challenges and opportunities posed by the implementation of the Convertibility regime, for which it is contextualized within the framework of the changes that had been operating in the international economic order from the 1970s, also noting the difficulties encountered by the development pattern of import substitution existing in Latin America by then.

Then the conditions that led to the hyperinflationary crisis of 1989 and 1990 Argentina -within the financial valuation model introduced in the country since 1976- and served as a prelude to the implementation of the Convertibility regime are analyzed, to then review briefly the main features of the economic plan signed by fixing the exchange rate, deregulation of the economy, trade liberalization and the sale of public assets.
\end{abstract}

*Artículo elaborado en base a la beca de Iniciación a la Investigación otorgada por la Secretaria General de Ciencia y Técnica UNNE (Res. 696/06 - CS) bajo la dirección de la Mgter. Alicia Carlino. 
Finally, we report the strategies adopted by local companies in light of the opportunities and challenges that were presented, characterized by a decrease in the number of production facilities, increasing trade openness, an investment process based on the acquisition of imported equipment, increased concentration and denationalization of the economy and the sharp drop in the ratio of value added, to conclude with a summary of the changes that these strategies occurred in the morphology of the country's productive apparatus, highlighting the strong momentum of services -especially for financial sector- and the reduction of value added in the production of goods for intensive activities in both capital and natural resources. Sin embargo, es natural preguntarse cómo un modelo que presupone la inexistencia de problemas de coordinación entre los agentes económicos puede arrojar luz sobre fenómenos macroeconómicos que tienen intrínsecamente que ver con este tipo de problemas. Dado que en un sistema complejo el comportamiento agregado no puede deducirse a partir de un análisis de los individuos aislados, los modelos de agente representativo no permiten abordar las preguntas básicas de la macroeconomía.

Keywords: Convertibility - Business Strategy - GDP structure.

\section{INTRODUCCIÓN}

El Régimen de Convertibilidad significó la culminación de un proceso de transformación de la economía argentina así como un enorme desafío para el entramado productivo del país. Con la adopción del sistema de caja de conversión y la sujeción de la moneda nacional al dólar se clausuraba una etapa signada por la inestabilidad tanto política como económica, el estancamiento productivo y la alta inflación; al tiempo que se daba comienzo a un período de crecimiento económico con deterioro del nivel de vida para amplios sectores de la población y un importante crecimiento del endeudamiento externo que desembocaría en el default de 2001.

\section{CRISIS DEL ESTADO DE BIENESTAR}

Hacia fines de la década de 1960 y principios de la de 1970 comenzó a percibirse en las economías del mundo capitalista una serie de transformaciones que preanunciaban la apertura de un período signado por la inestabilidad. El orden económico internacional de posguerra y sus instituciones, basadas en el estado de bienestar y en las políticas keynesianas, transitaron un ciclo de crecientes cuestionamientos ante el fuerte descenso de las tasas de crecimiento del producto y de la rentabilidad de las empresas, que afectaban también las condiciones de vida de la población, incluso en los países más industrializados ${ }^{1}$.

${ }_{1}^{1}$ Para un completo panorama de la crisis mundial de los '70 véase el excelente trabajo de Maddison (1992). 


\section{Cuadro 1: PIB per cápita}

Crecimiento anual promedio

\begin{tabular}{|l|c|c|}
\hline & $\mathbf{1 9 5 0 - 7 3}$ & $\mathbf{1 9 7 3 - 8 7}$ \\
\hline Alemania & $5,9 \%$ & $1,8 \%$ \\
Francia & $5,1 \%$ & $2,2 \%$ \\
Gran Bretaña & $3,0 \%$ & $1,6 \%$ \\
Japón & $9,3 \%$ & $3,7 \%$ \\
Estados Unidos & $3,7 \%$ & $2,5 \%$ \\
\cline { 2 - 3 } OCDE & $4,9 \%$ & $2,4 \%$ \\
Latinoamérica & $5,2 \%$ & $2,9 \%$ \\
\hline
\end{tabular}

Fuente: The Groningen Growth and Development Centre.

Aunque el sector monetario y financiero tuvo un papel destacado en la génesis y propagación de los crecientes desequilibrios tanto en el orden interno de las principales potencias como en las relaciones económicas internacionales, ya a partir de fines de la década de 1960 empezaron a manifestarse problemas en la producción, que fueron los verdaderos responsables de la ruptura de la tan mentada edad de oro del capitalismo.

Cuadro 2: PIB por hora hombre

Crecimiento anual promedio

\begin{tabular}{|l|c|c|}
\hline & $\mathbf{1 9 5 0 - 7 3}$ & $\mathbf{1 9 7 3 - 8 6}$ \\
\hline Alemania & $6,0 \%$ & $3,0 \%$ \\
Francia & $5,0 \%$ & $3,4 \%$ \\
Gran Bretaña & $3,2 \%$ & $2,5 \%$ \\
Japón & $7,6 \%$ & $3,1 \%$ \\
Estados Unidos & $2,4 \%$ & $1,2 \%$ \\
\cline { 2 - 3 } OCDE & $4,8 \%$ & $2,6 \%$ \\
Latinoamérica & $3,6 \%$ & $1,2 \%$ \\
\hline
\end{tabular}

Fuente: UNCTAD (1988).

La caída en las tasas de crecimiento de los países industrializados era señal de la progresiva desaceleración del ritmo de incremento en la productividad. Esto condujo a una disminución de las tasas de ganancia, que llevó a las empresas a reducir paulatinamente sus niveles de inversión. Por un tiempo, sin embargo, se mantuvo la tendencia ascendente de los salarios, pero luego éstos comenzaron a detener también su impulso. Resultaba claro entonces la forma en que se iba desarticulando el círculo virtuoso de incrementos en la productividad, la inversión y el salario, que había caracterizado a las dos décadas anteriores. 
Cuadro 3: FBKF

Crecimiento anual promedio

\begin{tabular}{|l|c|c|}
\hline & $\mathbf{1 9 5 0 - 7 3}$ & $\mathbf{1 9 7 3 - 8 4}$ \\
\hline Alemania & $5,4 \%$ & $3,4 \%$ \\
Francia & $3,6 \%$ & $4,0 \%$ \\
Gran Bretaña & $3,3 \%$ & $2,5 \%$ \\
Japón & $8,0 \%$ & $3,4 \%$ \\
Estados Unidos & $3,3 \%$ & $2,8 \%$ \\
\cline { 2 - 3 } OCDE & $4,7 \%$ & $3,2 \%$ \\
Latinoamérica & $4,7 \%$ & $5,0 \%$ \\
\hline
\end{tabular}

Fuente: Banco Mundial (1988).

La nueva coyuntura sorprendió a quienes habían predicho que, con las políticas keynesianas de estimulo de la demanda, las crisis económicas podían ser contenidas. Ello se relacionaba con la percepción de que las crisis pasadas se habían debido de manera fundamental a insuficiencias de demanda. Se vivía el idílico sueño de un mundo sin depresiones económicas donde el Estado garantizaba el ritmo de crecimiento del producto.

Desde el punto de vista productivo, la crisis impulsó los primeros intentos de restructuración en dos aspectos principales. Por un lado el agotamiento del modelo fordista dio paso a nuevas formas de organización del proceso de producción -como el toyotismo en Japón-. Este tipo de producción intentaba flexibilizar al máximo la organización del trabajo, de modo tal que la producción pudiese adaptarse fácilmente a cual quier cambio en la demanda, tanto cuantitativo como cualitativo. También representó un avance hacia nuevas modalidades de contratación y de trabajo ${ }^{2}$.

El segundo aspecto estuvo dado por el cambio en la estrategia del gran capital, que inició una etapa de expansión multinacional, segmentando su producción en procura de generar una nueva división internacional del trabajo. En términos generales la producción tendió a mundializarse debido a la expansión de las actividades de las corporaciones internacionales, mediante la instalación de filiales.

Los criterios que guiaron este proceso se relacionaron con las ventajas que presentaba el país en el que se situaba la filial, que en el aspecto económico podía consistir en la existencia de salarios e insumos más baratos, en la optimización del aprovechamiento de innovaciones tecnológicas o en el potenciamiento de su capacidad financiera gracias a las diferencias en las tasas de inflación de los diversos países y a los periódicos reacomodamientos del tipo de cambio; y en la esfera política, en la posibilidad de contarcon condiciones de privilegio que pueden explicarse por la existencia de asimetrías de poder en el orden internacional 3 .

\footnotetext{
${ }^{2}$ Las transformaciones productivas tendrían un profundo impacto en la situación argentina a posterioridad cuando, merced a la apertura económica, las firmas locales se vieron obligadas a competir con estas multinacionales en condiciones de atraso tecnológico y obsolescencia de sus métodos y procesos de producción. La destrucción creadora -en términos schumpeterianos- haría sentir sus efectos negativos en el entramado productivo local.

${ }^{3}$ En la Argentina dicho proceso se reflejó en la desarticulación de las cadenas productivas existentes y la mayor presencia de componentes importados dentro de la producción nacional. Comenzaba así a revertirse la tendencia hacia la integración productiva que había dominado las cuatro décadas anteriores.
} 


\section{EL AGOTAMIENTO DE LA INDUSTRIALIZACIÓN SUSTITUTIVA}

$\mathrm{Al}$ mismo tiempo en América Latina comenzaba a evidenciarse que, a pesar de que la sustitución de importaciones merecía crédito por tres décadas de rápido crecimiento económico, existían claros signos de pérdida de dinamismo y síntomas de desequilibrios macroeconómicos crecientes.

El fortalecimiento de sectores oligopólicos reticentes a la innovación y de baja competitividad a nivel internacional, la persistencia de un patrón de integración económica internacional caracterizado por una fuerte vulnerabilidad y volatilidad, y la insatisfactoria creación de puestos de trabajo como resultado de la elevada intensidad de capital que requerían las nuevas inversiones fueron síntomas del agotamiento del modelo.

Otro proceso significativo del periodo fue el endeudamiento facilitado por la amplia disponibilidad de liquidez internacional y la transnacionalización de las instituciones bancarias ${ }^{4}$. Desde mediados de la década de 1970 el mercado de préstamos internacionales se hizo cada vez más competitivo y la demanda de créditos de los países en desarrollo creció vertiginosamente. En dicho contexto, América Latina resultó la región hacia donde se dirigió la mayor parte del crédito, destacándose la Argentina, el Brasil y México que, en conjunto, recibieron el $80 \%$ de los préstamos otorgados.

Cuadro 4: Endeudamiento Externo

Crecimiento anual promedio

\begin{tabular}{|l|c|c|}
\hline & $\mathbf{1 9 7 3 - 8 2}$ & $\mathbf{1 9 8 2 - 8 6}$ \\
\hline Argentina & $88,0 \%$ & $1,5 \%$ \\
Brasil & $67,5 \%$ & $4,2 \%$ \\
Chile & $49,5 \%$ & $3,0 \%$ \\
Colombia & $38,2 \%$ & $10,5 \%$ \\
México & $95,0 \%$ & $3,4 \%$ \\
\cline { 2 - 3 } Perú & $29,1 \%$ & $6,3 \%$ \\
Latinoamérica & $66,6 \%$ & $5,1 \%$ \\
\hline
\end{tabular}

Fuente: Banco Mundial (1990).

La deuda externa de América Latina aumentó rápidamente durante la década de $1970^{5}$ hasta que a comienzos de la década de 1980 el aumento de las tasas de interés a nivel mundial combinado con la moratoria mexicana hizo cesar todo el flujo de préstamos a la región (Rapoport, 2005). Los efectos de este proceso de endeudamiento fueron fuertemente negativos para los países de la región. En la mayoría de ellos se detuvo por completo el crecimiento económico después de la crisis mexicana, dando por resultado lo que se dio en llamar la “década perdida" latinoamericana.

\footnotetext{
${ }^{4}$ Mientras que en 1973 la compraventa diaria de divisas representaba el 200\% del comercio mundial, para 1980 alcanzaba el 1000\%, para 1992 el 5000\% y para 1995 el 7000\% (Eatwell y Taylor, 2005).

${ }^{5}$ Téngase en cuenta que en 1960 la deuda global de la región ascendía a USD 7.200 millones pasando a 20.900 en 1970 , y a 243.000 en 1980 . Es decir un aumento del $290 \%$ y $1.162 \%$ respectivamente.
} 


\section{Cuadro 5: PIB per cápita}

Crecimiento anual promedio

\begin{tabular}{|l|c|c|}
\hline & $\mathbf{1 9 5 0 - 7 3}$ & $\mathbf{1 9 7 3 - 8 4}$ \\
\hline Argentina & $-1,0 \%$ & $-0,1 \%$ \\
Brasil & $2,5 \%$ & $2,3 \%$ \\
Chile & $0,0 \%$ & $1,0 \%$ \\
Colombia & $2,2 \%$ & $1,4 \%$ \\
México & $3,8 \%$ & $-2,6 \%$ \\
Perú & $0,6 \%$ & $-1,8 \%$ \\
Latinoamérica & $1,6 \%$ & $-0,1 \%$ \\
\hline
\end{tabular}

Fuente: Banco Mundial (1995).

Así a partir de la década de los ochenta, y más intensamente en la década siguiente, se implementaron en la región una serie de políticas de reforma e integración comercial-conocidas comúnmente como el Consenso de Washington- cuyo objetivo fue abandonar el modelo de sustitución de importaciones y promover un patrón de crecimiento orientado hacia el exterior.

Por casi dos décadas los países latinoamericanos llevaron adelante ambiciosos programas de liberalización comercial a través de la eliminación de la mayor parte de las restricciones no-arancelarias, la reducción de los aranceles ${ }^{6}$, la implementación de los acuerdos multilaterales ${ }^{7}$ y la puesta en marcha de acuerdos comerciales preferenciales más amplios y sustantivos (Bouzas y Ffrench-Davis, 2005).

Resumiendo, el endeudamiento de la región a tasas del mercado libre durante la década de 1970 y principios de la de 1980 tornó a América Latina especialmente vulnerable a los cambios en la coyuntura económica y financiera internacional. Luego de la crisis mexicana, las modalidades del ajuste en cada país quedaron sujetas a los dictados de los acreedores, los cuales vieron una oportunidad para forzar a los gobiernos lat inoamericanos a reprogramar sus deudas en función de reformas estructurales que abrieran aún más sus economías y redujeran el papel del Estado.

Es tiempo de analizar la modalidad que adquirieron dichas reformas en la Argentina -en el marco del Régimen de Convertibilidad-; pero primeramente resulta de utilidad analizar el contexto en el que fue implementado el plan.

\footnotetext{
${ }^{6}$ Cuyo promedio simple pasó del $45 \%$ a principios de los ' 80 al $13 \%$ en los ' 90.

${ }^{7}$ De modo que América Latina está entre las regiones en desarrollo con una mayor proporción de aranceles consolidados (100\%).
} 


\section{LA CRISIS HIPERINFLACIONARIA EN LA ARGENTINA}

A fines de la década de 1980, el proceso de acumulación basado en la valorización financiera comenzó a dar muestras inequívocas de agotamiento. Este régimen de acumulación se había consolidado a partir de la reforma financiera de 1977 y de la apertura comercial y financiera de 1979; caracterizándose por una drástica redistribución del ingreso en perjuicio de los sectores asalariados y -paradójicamente o no tanto- una fuerte intervención del Estado como canalizador de los recursos a los sectores más concentrados del capital nacional y extranjero, a través de subsidios como el de los regímenes especiales de promoción industrial, las transferencias al sistema financiero como la cuenta de regulación monetaria o los seguros de cambio, y el pago de intereses a los titulares de la deuda externa ${ }^{8}$. Aunque el gobierno constitucional instaurado a partir de 1983 intentó modificar la situación heredada, las restricciones impuestas por el endeudamiento externo lo convirtieron en algo imposible. Fue así que entre 1989 y 1990 se asistió a la virtual quiebra del Estado de manera tal que el nuevo gobierno de Carlos Menem intentó - a través de un conjunto de políticas económicas que culminarían en el Plan de Convertibilidad- encontrar una salida a la situación de bancarrota, con la economía sumida en una brutal crisis hiperinflacionaria y recesiva, adaptando sus políticas económicas a los intereses de los acreedores externos y de los grandes conglomerados locales y extranjeros.

La traumática experiencia de hiperinflación y recesión, el deterioro de las cuentas fiscales, el elevado endeudamiento, el retroceso de las reservas y la huida de capitales persuadieron al nuevo gobierno de abandonar sus promesas electorales y buscar el apoyo de los principales actores económicos, tanto domésticos como foráneos. De esta manera, priorizándose el retorno a la estabilidad, se produjo un rápido viraje hacia un programa económico de corte liberal, que reflejaba los intereses de las grandes empresas nacionales y extranjeras radicadas en la Argentina, la gran banca nacional y los representantes de los acreedores externos.

\section{RESEÑA DEL PLAN DE CONVERTIBILIDAD}

El Congreso Nacional sancionó en 1991 la Ley de Convertibilidad, cuya característica principal fue instaurar nuevamente un tipo de cambio fijo entre la moneda local y el dólar estadounidense (a la sazón diez mil australes por dólar), lo cual -en un entorno de hiperinflaciónse esperaba que devolviera la confianza de los mercados y de los agentes económicos locales. Se reformó también la Carta Orgánica del Banco Central para adecuarla al nuevo esquema, prohibiendo la emisión de moneda sin respaldo (en particular para financiar los déficits fiscales), en un contexto de política monetaria pasiva, que era dependiente de la posición neta de divisas. Asimismo en 1992, y en el marco del Plan Brady, el gobierno nacional alcanzó un acuerdo con los acreedores externos por el cual se remplazaba la deuda de capital e intereses atrasados con los bancos por bonos públicos de largo plazo con garantía9.

\footnotetext{
${ }_{8}$ Procesos ambos, el de la hipertrofia financiera y el endeudamiento externo, relacionados con la coyuntura de alta liquidez mundial que como se ha visto anteriormente tuvo sus orígenes en el quiebre del orden monetario internacional de posguerra y la masiva transferencia de recursos a las naciones exportadoras de petróleo - reciclado de los petrodólares -.

${ }^{9}$ De manera que los bancos pudieron sanear sus quebrantos contingentes a costa de transferir el riesgo crediticio a los tenedores de bonos.
} 
El Plan de Convertibilidad era visto como un nuevo intento de estabilización pero acompañado de esfuerzos más profundos en materia de reforma del régimen de incentivos y de las instituciones regulatorias (Bisang et al., 1995). Su aplicación implicaba un amplio programa de reformas estructurales sustentadas en las recomendaciones del Consenso de Washington. Estas reformas pueden ser resumidas en: 1) El aumento del grado de apertura de la economía a la competencia externa; 2) La desregulación de múltiples mercados; 3) La privatización de activos del sector público en campos como telecomunicaciones, transporte, energía y puertos; y 4) El anclaje del tipo de cambio como forma de estabilizar los precios $^{10}$.

$\mathrm{Al}$ cambio de régimen interno se le sumaron, durante los primeros años de funcionamiento del modelo, una serie de hechos internacionales que afectaron positivamente a la economía doméstica. Entre ellos se encuentra el refinanciamiento de la deuda externa, la abrupta caída de la tasa de interés internacional y la consecuente reaparición masiva de financiamiento externo (Damill et al., 1993). Este conjunto de factores determinó un efecto positivo sobre las expectativas de ingresos futuros que impulsaron aumentos en el consumo (producto del crecimiento de la oferta de crédito local e internacional) y generaron nuevas oportunidades de inversión. Asimismo, la desaceleración del proceso inflacionario, determinó un aumento de la demanda agregada difundido en los distintos sectores de la economía, lo cual permitió un incremento de los ingresos tributarios y, por lo tanto, una mejora de las cuentas fiscales. Esta ruptura con el pasado inflacionario se constituyó en un elemento crucial para la evolución de las actividades económicas, dada su importancia para la formación de precios y la demanda de activos.

Cuadro 6: PIB per cápita

Crecimiento anual promedio

\begin{tabular}{|c|c|c|}
\hline & PIB & IED \\
\hline 1991 & $34,2 \%$ & $32,8 \%$ \\
1992 & $20,6 \%$ & $81,7 \%$ \\
1993 & $3,5 \%$ & $-37,0 \%$ \\
1994 & $8,7 \%$ & $30,1 \%$ \\
1995 & $0,2 \%$ & $54,3 \%$ \\
1996 & $5,5 \%$ & $23,9 \%$ \\
1997 & $7,6 \%$ & $31,8 \%$ \\
1998 & $2,1 \%$ & $-20,4 \%$ \\
1999 & $-5,2 \%$ & $229,0 \%$ \\
2000 & $0,2 \%$ & $-56,6 \%$ \\
2001 & $-5,5 \%$ & $-79,2 \%$ \\
\hline
\end{tabular}

Fuente: Fondo Monetario Internacional (2003).

\footnotetext{
${ }^{10}$ Inspirado en el enfoque monetario de la balanza de pagos.
} 
En relación a la reforma del funcionamiento y alcance del Estado, se sancionó una ley que declaró sujetas a privatización o concesión a un amplio conjunto de empresas y actividades del sector público. Este proceso se desarrolló con suma celeridad. Tal fue así que en el año 1990 fueron traspasadas al sector privado las empresas de telefonía (ENTel) y de aeronavegación (Aerolíneas Argentinas); y en años posteriores fueron seguidas por activos petroleros (1991 y 1992), las empresas de electricidad y gas (1992), la siderúrgica estatal SOMISA (1992) y la petrolera YPF (1993), entre otras operaciones (Kosacoff y Ramos, 2005).

\section{CAMBIOS EN LA ESTRUCTURA PRODUCTIVA ARGENTINA}

La causa -y a la vez consecuencia si se lo piensa como un proceso recursivo- de las estrategias microeconómicas adoptadas vino de la mano de los cambios operados en el aparato productivo de la Argentina, y que pueden observarse a nivel de los agregados macroeconómicos si se analiza la composición sectorial del Producto Interno Bruto (PIB). Allí se evidencia que entre los años 1993 y 2001 el sector productor de bienes creció en su conjunto un 6,34\% siendo superado por los servicios que crecieron un $17,22 \%$ en el mismo período; resultando una clara señal de los efectos perjudiciales que tuvo la apertura económica irrestricta.

\section{Cuadro 7: Evolución Sectorial del PIB}

Variación acumulada 1993-2001

\begin{tabular}{|ll|}
\hline Sector Primario & $26,49 \%$ \\
Agricultura, Ganadería y Silvicultura & $22,85 \%$ \\
Resto & $38,32 \%$ \\
Pesca & $31,17 \%$ \\
Explotación de Minas y Canteras & $39,65 \%$ \\
Industria Manufacturera & $-4,33 \%$ \\
Suministro de Electricidad, Gas y Agua & $49,42 \%$ \\
Construcciones & $-1,47 \%$ \\
SECTORES PRODUCTORES DE BIENES & $\mathbf{6 , 3 4 \%}$ \\
\hline Comercio, Hoteles y Restaurantes & $4,35 \%$ \\
Comercio Mayorista y Minorista & $1,02 \%$ \\
Hoteles y Restaurantes & $23,24 \%$ \\
Transporte, Comunicaciones e Intermediación Financiera & $44,04 \%$ \\
Transporte, Almacenamiento y Comunicaciones & $34,85 \%$ \\
Intermediación Financiera & $59,16 \%$ \\
Actividad Inmobiliaria, Empresarial y de Alquiler & $14,94 \%$ \\
Administración Pública y Defensa & $-2,93 \%$ \\
Enseñanza, Servicios Sociales y de Salud & $21,50 \%$ \\
Otras Actividades de Servicio & $19,68 \%$ \\
SECTORES PRODUCTORES DE SERVICIOS & $\mathbf{1 7 , 2 2} \%$ \\
PRODUCTO INTERNO BRUTO & $\mathbf{1 2 , 4 3 \%}$ \\
\hline
\end{tabular}

Fuente: Dirección Nacional de Cuentas Nacionales. 
Si ahora se centra la atención al interior de la producción se encuentra con que las industrias manufactureras -tradicionales generadoras de empleo, capacidades tecnológicas e integración económica- permanecieron prácticamente estancadas contrayéndose un 4,33\% a lo largo de esos años. Este pobre desempeño fue consecuencia de la brusca apertura de la producción local a la competencia extranjera en momento en que, como se ha visto, ésta había concluido su proceso de modernización y adecuación a las prácticas del nuevo mundo crecientemente globalizado.

Siguiendo dentro del sector productor de bienes el suministro de electricidad, gas y agua; de la misma manera que la explotación de minas y canteras, tuvieron desempeños destacados ${ }^{11}$, signos de la primarización de la economía argentina. De esta manera la apertura externa, al modificar los precios relativos y exponer a las empresas locales a la competencia internacional, desalentó la producción en las actividades más intensivas en el uso de la mano de obra; y por contrapartida desvió los esfuerzos económicos hacia sectores más intensivos en el uso de los recursos naturales y el capital ${ }^{12}$. De manera tal que, mientras en 1993 había un claro predominio de las manufacturas dentro de la producción de bienes (54,04\%), su pobre performance durante la vigencia del Régimen de Convertibilidad generó una estructura más heterogénea donde las manufacturas tenían un liderazgo más ajustado (47,54\%) seguido aún por la agricultura y la construcción ${ }^{13}$ (Bisang, 1995).

Pero el cuadro general se agrava al considerar la producción de servicios ${ }^{14}$ ya que, como se ha dicho, ésta creció más aún que la producción de bienes $(17,22 \%)$ y estuvo liderada por la intermediación financiera $(59,16 \%)^{15}$ que se vio estimulada por una moneda sobrevaluada y el masivo ingreso de capitales al país. De la misma manera también hubo, dentro de la producción de servicios, cambios en la participación de cada una de las actividades, pero éstos fueron de menor relevancia.

\section{ESTRATEGIAS EMPRESARIALES}

Una vez expuestos los rasgos principales de la política económica implementada a partir de 1991 puede echarse un vistazo a lo ocurrido al interior de las empresas. Tenemos así que la respuesta de las firmas a las transformaciones estructurales producidas no se hizo esperar y adquirió características significativas. Comenzaron a desplegarse fuertes procesos de reconversión empresarial, en los cuales se alteraron tanto las estrategias como el peso relativo de las distintas actividades y agentes económicos, así como las prácticas productivas, tecnológicas y comerciales.

Resulta importante señalar aquí que, a la retirada de las empresas estatales (vía privatizaciones), y cierta involución de las pequeñas y medianas empresas, se suma la reorganización de los conglomerados económicos locales; y el liderazgo y sostenido dinamismo de las empresas transnacionales.

\footnotetext{
${ }^{11} 49,42 \%$ y $39,65 \%$ respectivamente.

${ }^{12}$ Y por lo tanto menos aptos para la generación de empleo.

${ }^{13}$ La agricultura ascendió del 19,07 al 19,98\% entre 1991 y 2001; y la Construcción del 16,45 al 16,57\%.

${ }^{14}$ Sector no transable por definición y por lo tanto resguardado de la competencia externa (Blanchard y Pérez Enrri, 2000).

${ }^{15}$ Pasó de $\$ 9.299$ millones a $\$ 13.762$ millones.
} 
Cuadro 8: FBKF

Crecimiento anual y relación con el PIB

\begin{tabular}{|c|c|c|}
\hline & Var. & \%PIB \\
\hline 1991 & $40,4 \%$ & $14,6 \%$ \\
1992 & $37,6 \%$ & $16,7 \%$ \\
1993 & $18,1 \%$ & $19,1 \%$ \\
1994 & $13,8 \%$ & $19,9 \%$ \\
1995 & $-9,8 \%$ & $17,9 \%$ \\
1996 & $6,3 \%$ & $18,1 \%$ \\
1997 & $15,3 \%$ & $19,4 \%$ \\
1998 & $5,1 \%$ & $19,9 \%$ \\
1999 & $-14,3 \%$ & $18,0 \%$ \\
2000 & $-9,9 \%$ & $16,2 \%$ \\
2001 & $-17,2 \%$ & $14,2 \%$ \\
\hline
\end{tabular}

Fuente: Banco Mundial (2005).

Dentro del universo de empresas productivas hay que destacar el comportamiento de éstas empresas transnacionales, cuyas estrategias estuvieron asociadas a los flujos de inversión extranjera directa que ingresaron durante la década de 1990, primero por su participación en las privatizaciones y, posteriormente, por la adquisición de los activos existentes. Estas inversiones lideraron el proceso de reconversión productiva de esos años, en especial en los aspectos modernizadores del proceso, destacándose la elevada correlación entre los sectores más dinámicos de la producción local y el aumento de la participación del capital extranjero.

\section{Cuadro 9: Evolución de las Empresas Transnacionales}

Participación de empresas transnacionales en ventas por sector de actividad. Porcentajes.

\begin{tabular}{|l|c|c|}
\hline & 1990 & 1998 \\
\hline Servicio telefónico & $93,4 \%$ & $100,0 \%$ \\
Automóviles y autopartes & $92,0 \%$ & $99,7 \%$ \\
Electricidad, gas y agua & $0,0 \%$ & $98,3 \%$ \\
Informática, telefonía, productos eléctricos, automatización e instrumental & $94,1 \%$ & $98,3 \%$ \\
Química y petroquímica & $57,0 \%$ & $88,0 \%$ \\
Celulosa y papel & $1,1 \%$ & $74,6 \%$ \\
Minería & $27,1 \%$ & $65,9 \%$ \\
Comercio de importación asociado a asistencia técnica & $100,0 \%$ & $64,6 \%$ \\
Otras manufacturas & $48,0 \%$ & $64,3 \%$ \\
Farmacéutica & $61,7 \%$ & $62,8 \%$ \\
Industria plástica y productos de caucho & $68,8 \%$ & $58,0 \%$ \\
Aceites y granos & $50,3 \%$ & $57,4 \%$ \\
\hline
\end{tabular}




\begin{tabular}{|l|c|c|}
\hline Pesca & $36,3 \%$ & $57,3 \%$ \\
Editorial, industria gráfica & $0,0 \%$ & $54,0 \%$ \\
Transporte y almacenamiento & $33,5 \%$ & $52,8 \%$ \\
Comercio mayorista y minorista & $20,1 \%$ & $52,7 \%$ \\
Petróleo y combustibles & $31,7 \%$ & $49,2 \%$ \\
Alimentos, bebidas y tabaco & $33,7 \%$ & $49,2 \%$ \\
Electrodomésticos y electrónica de consumo & $40,4 \%$ & $47,8 \%$ \\
TV y multimedia & $0,0 \%$ & $44,7 \%$ \\
Vidrio y minerales no metálicos & $20,8 \%$ & $44,1 \%$ \\
Otros servicios & $12,9 \%$ & $40,7 \%$ \\
Metalurgia y maquinarias & $25,5 \%$ & $37,4 \%$ \\
Cuero y sus manufacturas & $35,2 \%$ & $37,0 \%$ \\
Trading de productos primarios & $23,2 \%$ & $36,6 \%$ \\
Textiles y prendas de vestir & $6,1 \%$ & $16,8 \%$ \\
Frigoríficos & $17,6 \%$ & $15,2 \%$ \\
Construcción e ingeniería & $13,1 \%$ & $14,9 \%$ \\
Siderurgia y aluminio & $0,0 \%$ & $3,7 \%$ \\
Varios & $1,1 \%$ & $0,0 \%$ \\
Total & $34,5 \%$ & $58,9 \%$ \\
\hline
\end{tabular}

Fuente: Azpiazu, D.; Basualdo, E., y Schorr, M. (2000).

La consolidación en el sector industrial de grandes firmas pertenecientes a conglomerados empresarios -de origen nacional o extranjero- no constituyó un fenómeno novedoso, ya que se trata de un proceso que se venía registrando con particular intensidad en el país desde fines del decenio de los setenta. Lo particular de esta época radicó en la notable expansión que registraron las empresas oligopólicas de origen extranjero. En el caso de los conglomerados extranjeros, cabe destacar que durante la primera mitad del período evidenciaron una muy importante participación al interior del sector mientras que a partir de 1995 se consolidan como la tipología empresaria de mayor peso estructural del conjunto del sector. Las empresas transnacionales, por su parte, que presentaron una reducida presencia en la actividad a comienzos del decenio para expandirse significativamente durante la segunda mitad, a tal punto que hacia fines del período analizado lograron consolidarse como el segundo segmento empresario de mayor importancia (Azpiazú et ál., 2000). 


\section{Cuadro 10: Evolución de las Empresas Transnacionales}

Participación de empresas transnacionales en ventas, exportaciones e importaciones por sector de actividad. Porcentajes.

\begin{tabular}{|l|c|c|c|c|c|c|}
\hline & \multicolumn{2}{|c|}{ Ventas } & \multicolumn{2}{c|}{ Exportaciones } & \multicolumn{2}{c|}{ Importaciones } \\
\hline & 1992 & $\mathbf{1 9 9 8}$ & $\mathbf{1 9 9 2}$ & $\mathbf{1 9 9 8}$ & $\mathbf{1 9 9 2}$ & $\mathbf{1 9 9 8}$ \\
\hline Servicio telefónico & $95,1 \%$ & $100,0 \%$ & $\mathrm{~s} / \mathrm{d}$ & $100,0 \%$ & $98,4 \%$ & $98,7 \%$ \\
Automóviles y autopartes & $94,4 \%$ & $99,7 \%$ & $92,0 \%$ & $98,9 \%$ & $95,4 \%$ & $97,9 \%$ \\
Electricidad, gas y agua & $3,1 \%$ & $98,3 \%$ & $0,0 \%$ & $100,0 \%$ & $72,0 \%$ & $98,3 \%$ \\
Informática, telefonía, productos & $95,9 \%$ & $98,3 \%$ & $93,9 \%$ & $68,8 \%$ & $96,3 \%$ & $94,2 \%$ \\
eléctricos, automatización e instrumental & & & & & & \\
Química y petroquímica & $66,4 \%$ & $88,0 \%$ & $53,5 \%$ & $73,1 \%$ & $77,0 \%$ & $88,2 \%$ \\
Celulosa y papel & $8,7 \%$ & $74,6 \%$ & $4,7 \%$ & $91,2 \%$ & $65,8 \%$ & $68,3 \%$ \\
Minería & $36,2 \%$ & $65,9 \%$ & $0,0 \%$ & $98,6 \%$ & $46,7 \%$ & $89,6 \%$ \\
Farmacéutica & $43,1 \%$ & $62,8 \%$ & $56,1 \%$ & $69,9 \%$ & $68,9 \%$ & $76,3 \%$ \\
Aceites y granos & $37,0 \%$ & $57,4 \%$ & $43,6 \%$ & $62,4 \%$ & $50,6 \%$ & $44,8 \%$ \\
Transporte y almacenamiento & $36,2 \%$ & $52,8 \%$ & s/d & $100,0 \%$ & $39,8 \%$ & $35,0 \%$ \\
Vidrio y minerales no metálicos & $23,5 \%$ & $44,1 \%$ & $40,7 \%$ & $59,2 \%$ & $32,0 \%$ & $45,7 \%$ \\
Construcción e ingeniería & $14,6 \%$ & $14,9 \%$ & $7,8 \%$ & $58,3 \%$ & $51,2 \%$ & $58,8 \%$ \\
\hline Total & $38,1 \%$ & $58,9 \%$ & $37,6 \%$ & $54,3 \%$ & $61,9 \%$ & $71,7 \%$ \\
\hline
\end{tabular}

Fuente: Azpiazu, D.; Basualdo, E., y Schorr, M. (2000).

De este modo, la transformación de la estructura productiva, impulsada por el conjunto de incentivos implícitos y explícitos del programa de reformas estructurales implementado; y la estructura de precios y rentabilidades de un tipo de cambio nominal fijo, generaron un sesgo en contra de la producción de bienes internacionalmente transables y a favor de la expansión de los servicios, como se vio anteriormente, así como un relativo abaratamiento del capital con respecto al costo doméstico de la mano de obra, estimulado por el acceso irrestricto al equipamiento importado y a abundantes fondos internacionales. Ambos sesgos tendieron a favorecer el desarrollo de aquellas actividades más intensivas en capital y relativamente protegidas o cercanas a las ventajas naturales en desmedro de los procesos captadores de mano de obra con el consiguiente impacto negativo sobre la generación de empleo (Fernández Bugna y Porta, 2007).

Como producto de ello, las ramas de mayor crecimiento e importancia relativa del segmento industrial local -y de la cúpula empresaria del sector- se caracterizaron por presentar un reducido dinamismo en materia de generación de valor agregado. Así, la consolidación de este tipo de perfil sectorial en aquellas grandes firmas que podían definir el sendero por el que transitan tales actividades y, más en general, el conjunto de la industria, constituyó uno de los principales factores para explicar las causas por las que el sector continuó perdiendo peso relativo en el PBI global (Azpiazú et ál., 2000).

Por otra parte, los principales elementos que caracterizaron el desempeño microeconómico en la década de 1990 fueron la disminución del número de establecimientos productivos, el aumento del grado de apertura comercial (con mayor énfasis por el lado de las importacio- 
nes que de las exportaciones), un proceso de inversiones basado en la adquisición de equipos importados, el aumento de la concentración y la extranjerización de la economía y la caída abrupta del coeficiente de valor agregado. Estas características hicieron que en un amplio conjunto de empresas se incrementaran los procesos de integración a redes de comercio internacional, lo cual permitió avanzar en la especialización y simplificación del mix de producción (debido a una mayor complementación con la oferta externa, especialmente en el caso de las automotrices dentro del Mercosur), simultáneamente con la desintegración productiva y el uso más preponderante de las cadenas comerciales.

La incorporación a estas redes determinó una mayor adopción de tecnologías de producto de nivel de "frontera tecnológica" y de origen externo, un abandono de la mayor parte de los esfuerzos tecnológicos locales en la generación de nuevos productos y procesos, una desverticalización de las actividades basadas en la sustitución de valor agregado local por abastecimiento externo y una creciente externalización de actividades del sector servicios (Kosacoff y Ramos, 2005).

Cuadro 10: Evolución Sectorial del Producto y del Empleo Argentina

PIB | Asalariados Registrados del sector privado. Variación acumulada 1996-2001

\begin{tabular}{|c|c|c|}
\hline & PBI & Empleo \\
\hline Sector Primario & $9,16 \%$ & $4,15 \%$ \\
\hline Agricultura, Ganadería y Silvicultura & $10,89 \%$ & $4,01 \%$ \\
\hline Resto & $5,93 \%$ & $5,64 \%$ \\
\hline Pesca & $18,16 \%$ & $17,36 \%$ \\
\hline Explotación de Minas y Canteras & $4,97 \%$ & $2,11 \%$ \\
\hline Industria Manufacturera & $-8,11 \%$ & $-9,00 \%$ \\
\hline Suministro de Electricidad, Gas y Agua & $27,10 \%$ & $9,40 \%$ \\
\hline Construcciones & $-3,51 \%$ & $8,84 \%$ \\
\hline SECTORES PRODUCTORES DE BIENES & $-0,89 \%$ & $-3,49 \%$ \\
\hline Comercio, Hoteles y Restaurantes & $-2,80 \%$ & $16,29 \%$ \\
\hline Comercio Mayorista y Minorista & $-4,70 \%$ & $16,99 \%$ \\
\hline Hoteles y Restaurantes & $7,42 \%$ & $12,71 \%$ \\
\hline Transporte, Comunicaciones e Intermediación Financiera & $20,02 \%$ & $19,26 \%$ \\
\hline Transporte, Almacenamiento y Comunicaciones & $15,93 \%$ & $21,22 \%$ \\
\hline Intermediación Financiera & $26,38 \%$ & $14,60 \%$ \\
\hline Actividad Inmobiliaria, Empresarial y de Alquiler & $5,41 \%$ & $29,41 \%$ \\
\hline Enseñanza, Servicios Sociales y de Salud & $12,78 \%$ & $32,52 \%$ \\
\hline Enseñanza & $s / d$ & $63,32 \%$ \\
\hline Servicios Sociales y de Salud & $s / d$ & $0,11 \%$ \\
\hline Otras Actividades de Servicio & $13,30 \%$ & $11,61 \%$ \\
\hline SECTORES PRODUCTORES DE SERVICIOS & $7,32 \%$ & $21,54 \%$ \\
\hline PIB | Total Asalariados Registrados del sector privado & $3,90 \%$ & $11,58 \%$ \\
\hline
\end{tabular}

Fuente: Dirección Nacional de Cuentas Nacionales (INDEC) y Observatorio de Empleo y Dinámica Empresarial (MTEySS). 
Durante la vigencia del régimen de convertibilidad el crecimiento de la producción estuvo vinculado con los ostensibles incrementos que se registraron en la productividad media de la mano de obra industrial. El aumento en la producción por obrero ocupado estuvo mucho más relacionado con el proceso de expulsión de asalariados que tuvo lugar durante el período analizado que con los incrementos productivos. Pero esos crecientes recursos generados por la mayor productividad de la mano de obra no tuvieron como correlato incrementos salariales sino que, por el contrario, lo que se verificó fue un persistente deterioro de las remuneraciones medias de los trabajadores. La conjunción de ambos fenómenos trajo aparejada una mayor regresividad en la distribución interna del ingreso fabril, lo cual denota que las fracciones más concentradas del capital se apropiaron de buena parte de los recursos generados por la mayor productividad y los menores salarios de la mano de obra (Azpiazú et al., 2000).

\section{CONCLUSIONES}

A lo largo del presente trabajo se pretendió vincular las transformaciones ocurridas en la economía mundial en las últimas décadas, con los desafíos que debieron afrontar las naciones latinoamericanas producto del agotamiento del patrón de desarrollo imperante y el tipo de respuesta que se evidenció en la Argentina tanto desde el punto de vista de las políticas macroeconómicas implementadas, como así también desde las estrategias microeconómicas adoptadas al interior de las firmas.

El orden económico internacional de la segunda posguerra comenzó a resquebrajarse a fines de la década de 1960 y comienzos de la de 1970 producto de los cambios en las relaciones de poder dentro del bloque de los países desarrollados. De manera tal que a partir del nuevo escenario emergente, se conformó un orden económico caracterizado por una mayor integración financiera y productiva -y en cierta medida comercial también- consignado por una menor intervención del Estado.

En el caso de los países latinoamericanos, esa reorganización del orden económico internacional se conjugó con los shocks petroleros y el agotamiento del esquema de desarrollo industrial basado en el mercado interno, para propiciar la irrupción masiva de capitales -merced a la liberalización de los flujos internacionales de capital y el reciclado de petrodólares- y el crecimiento inusitado de la deuda externa (primeramente privada, y con posterioridad pública también). Al mismo tiempo la reorganización productiva de las compañías multinacionales ${ }^{16}$ implicó el ensanchamiento de la brecha tecnológica para las firmas latinoamericanas cuyos efectos -aunque ya perceptibles en la década de 1970- se harían sentir con total intensidad a partir de la década de 1990.

Considerar la crítica situación de hiperinflación y virtual quiebra del Estado que precedió a la implantación del Régimen de Convertibilidad permite por un lado; contextualizar los condicionamientos que debió enfrentar la producción doméstica, y al mismo tiempo evidenciar el

\footnotetext{
${ }^{16}$ En términos schumpeterianos la "destrucción creadora" que provocó la/s crisis de los '70 tuvo como corolario el surgimiento de nueva empresas portadoras de procesos más eficientes.
} 
juego de incentivos explícitos e implícitos que operó sobre las empresas a efectos de aprovechar las oportunidades que se les presentaban.

La conjunción de un tipo de cambio fijo con la apertura comercial generó un sesgo favorable a la producción de bienes no transables -tercerización- al tiempo que desalentó la producción industrial de bienes de alta complejidad en favor de artículos intensivos en capital y recursos naturales -primarización-.

Ello se explica cuando se tiene en cuenta que las firmas adoptaron estrategias adaptativas tendientes a disminuir el número de establecimientos productivos, aumentar el grado de apertura comercial, conjuntamente con un proceso de inversiones basado en la adquisición de equipos importados, el aumento de la concentración y la extranjerización de la economía y la caída abrupta del coeficiente de valor agregado; por lo que un amplio conjunto de empresas incrementaron su integración a redes de comercio internacional, permitiéndoles avanzar en la especialización y simplificación de su mix de producción.

Finalmente, de ello resulta evidente cómo esas restricciones externas promovieron un patrón de especialización que, merced al tipo de cambio sobrevaluado y la eliminación de las restricciones a las importaciones, se orientó hacia la intermediación financiera y la producción de bienes intensivos en recursos naturales y capital, pero de escaso valor agregado al tiempo que los incrementos de productividad estuvieron lejos de reflejarse en aumentos salariales.

\section{REFERENCIAS BIBLIOGRÁFICAS.}

Azpiazu, D.; Basualdo, E., y Schorr, M. (2000) La reestructuración y el redimensionamiento de la producción industrial argentina durante las últimas décadas. Buenos Aires: FETIA-CTA.

Banco Mundial (1988) Tablas Mundiales. Washington.

Banco Mundial (1990) Flujos Mundiales de Financiamiento para el Desarrollo. Washington.

Banco Mundial (1995) Global economic prospects and the developing countries. Washington.

Bisang, R. et al. (1995) Hacia un nuevo modelo de organización industrial. El sector manufacturero argentino en los años 9o. Buenos Aires: Alianza Editorial / CEPAL / United Nations University Press.

Blanchard, O. y Pérez Enrri, D. (2000) Macroeconomía: Teoría y política económica con aplicaciones a América Latina. Buenos Aires: Pearson Education. 
Bouzas, R. y Ffrench-Davis, R. (2005) “Globalización y políticas nacionales: ¿̇cerrando el círculo?”. Desarrollo Económico. Vol. 45. № 179. Buenos Aires. Octubre-Diciembre, 323-348.

Chudnovsky, D. y López, A. (2001) La transnacionalización de la economía argentina en los años 1990. Buenos Aires: EUDEBA.

Damill, M. et al. (1993) “Crecimiento Económico en América Latina. Experiencias recientes y perspectivas”. Desarrollo Económico. Vol. 33. Julio-Septiembre. Buenos Aires.

Eatwell, J. y Taylor, L. (2005) Finanzas globales en riesgo. Un análisis a favor de la regulación internacional. Buenos Aires: Siglo XXI.

Fernández Bugna, C. y Porta, F. (2007) “El crecimiento reciente de la industria argentina. Nuevo régimen sin cambio estructural”. En Kosacoff, B. (ed.) Crisis, recuperación y nuevos dilemas. La economía argentina 2002-2007. Buenos Aires: CEPAL.

Fondo Monetario Internacional (2003) Estadísticas financieras internacionales. Washington.

Kosacoff, B. y Ramos, A. (2005) "Comportamientos microeconómicos en entornos de alta incertidumbre: la industria argentina”. Boletín Informativo Techint $N^{\circ} 318$. Buenos Aires, 73-104.

Maddison, A. (1992) La Economía Mundial en el Siglo XX: Rendimiento y Política en Asia, América Latina, la URSS y los países de la OCDE. México D.F.: FCE, 37-48.

Rapoport, M. (2005) Historia Económica, Política y Social de la Argentina (1880-2003). Buenos Aires: Ariel.

The Groningen Growth and Development Centre.

UNCTAD (1988) Trade and Development Report. 


\section{CURRICULUM VITAE}

\section{LUCAS M. GÓMEZ TONSICH.}

Contador Público egresado de la Facultad de Ciencias Económicas de la Universidad Nacional del Nordeste. Maestrando en Ciencias Sociales en la Universidad Nacional de Quilmes.

Desde 2005 Auxiliar Docente de Primera por Concurso en la Cátedra de Historia Económica de la Facultad de Ciencias Económicas de la Universidad Nacional del Nordeste.

Desde 2007 Becario de Investigación de la Secretaría General de Ciencia y Técnica de la Universidad Nacional del Nordeste bajo la dirección de la Mgter. Alicia Carlino.

\section{ltonsich@eco.unne.edu.ar}

